CLINICAL STUDY

\title{
Expression of ghrelin gene in peripheral blood mononuclear cells and plasma ghrelin concentrations in patients with metabolic syndrome
}

\author{
Ursula Mager $^{1}$, Marjukka Kolehmainen ${ }^{1}$, Vanessa D F de Mello ${ }^{1,3}$, Ursula Schwab ${ }^{1,2}$, David E Laaksonen ${ }^{2,5}$, \\ Rainer Rauramaa $^{4}$, Helena Gylling ${ }^{1,2}$, Mustafa Atalay ${ }^{5}$, Leena Pulkkinen ${ }^{1}$ and Matti Uusitupa ${ }^{1}$ \\ ${ }^{1}$ Department of Clinical Nutrition, School of Public Health and Clinical Nutrition, Food and Health Research Centre, University of Kuopio PO Box 1627 , \\ FIN-70211 Kuopio, Finland, ${ }^{2}$ Institute of Clinical Medicine, Internal Medicine, University of Kuopio and Kuopio University Hospital, PO Box 1777, FIN- \\ 70211 Kuopio, Finland, ${ }^{3}$ Department of Internal Medicine, Federal University of Rio Grande do Sul, 90035-003 Porto Alegre, Brazil, ${ }^{4}$ Kuopio Research \\ Institute of Exercise Medicine, Kuopio, Finland and ${ }^{5}$ Institute of Biomedicine, Physiology, University of Kuopio, PO Box 1627, FIN-70211 Kuopio, Finland
}

(Correspondence should be addressed to U Mager who is now at School of Public Health and Clinical Nutrition, University of Kuopio, Mediteknia Building, PO Box 1627, FIN-70211 Kuopio, Finland; Email: ursula.mager@uku.fi)

\begin{abstract}
Objective: We examined the expression of ghrelin and ghrelin receptors in peripheral blood mononuclear cells (PBMCs) and evaluated the effect of weight loss or exercise on plasma ghrelin concentrations in subjects with the metabolic syndrome.

Design and methods: Data from 75 overweight/obese subjects randomized to a weight loss, aerobic exercise, resistance exercise or control group for a 33-week intervention period were analysed. The plasma ghrelin concentrations and indices of insulin and glucose metabolism were assessed, and mRNA expression of ghrelin, its receptors and various cytokines in PBMCs was studied using real-time PCR.

Results: Ghrelin and GH secretagogue receptor $1 \mathrm{~b}$ were expressed in PBMCs of subjects with metabolic syndrome. Ghrelin gene expression correlated positively with the expressions of tumour necrosis factor- $\alpha(P<0.001)$, interleukin-1 $\beta(P<0.001)$ and interleukin-6 $(P=0.026)$ during the study, but was not associated with the plasma ghrelin concentration. Genotype-specific ghrelin gene expression in PBMCs was found for the $-604 \mathrm{G} / \mathrm{A}$ and the $-501 \mathrm{~A} / \mathrm{C}$ polymorphisms in the ghrelin gene. At baseline, the plasma ghrelin levels were associated with fasting serum insulin concentrations, insulin sensitivity index and high-density lipoprotein cholesterol. However, longitudinally weight, BMI or waist circumference and acute insulin response in i.v. glucose tolerance test were stronger predictors of the ghrelin concentration. Plasma ghrelin did not change over the study period in the weight reduction group, but it tended to decrease in the control group $(P=0.050)$.

Conclusions: Ghrelin mRNA expression in PBMCs suggests an autocrine role for ghrelin within an immune microenvironment. Moderate long-term weight loss may prevent a decline in ghrelin concentration over time in individuals with metabolic syndrome.
\end{abstract}

European Journal of Endocrinology 158 499-510

\section{Introduction}

Ghrelin, a 28-amino acid peptide, may influence the development of obesity and the metabolic syndrome through its role in the control of energy balance, food intake and regulation of body weight $(1,2)$. Insulin itself may also modulate the secretion of ghrelin $(3,4)$. Ghrelin is the only known endogenous ligand for the growth hormone secretagogue receptor (GHSR), and it strongly stimulates the release of growth hormone (GH) from the pituitary gland (5).

Acylation on the third serine residue of the ghrelin peptide is essential for at least the majority of its biological activities and the vast majority of circulating ghrelin has been found to be non-acylated (2).

The human ghrelin gene is located at the chromosomal locus 3p26-p25, and the prepro-hormone is encoded by five exons (2). In several studies, single nucleotide polymorphisms (SNPs) in the ghrelin gene have been associated with obesity (6-9), blood pressure (10), type 2 diabetes (11-14) and the metabolic syndrome $(15,16)$, although the results have not been consistent. To our knowledge, there are no studies showing genotypespecific expression of ghrelin in any tissue.

Although ghrelin is predominantly produced by the stomach, substantially lower amounts of ghrelin 
expression have been detected in most human organs and tissues $(5,17)$. Apart from regulation of GH release and energy balance, ghrelin may also modulate the immune system $(18,19)$.

The effects of ghrelin are mediated via the GHSR (20). Two distinct ghrelin receptor transcripts are known: GHSR type $1 \mathrm{a}$ acts as ghrelin receptor, whereas type $1 \mathrm{~b}$ is a truncated form of the GHSR 1a and pharmacologically inactive (20). The GHSR 1a is expressed mainly in the hypothalamus and pituitary gland $(17,21)$, while the GHSR type 1b mRNA expression has also been found in many peripheral organs (21), including immune cells $(18,19)$, indicating that ghrelin may have multiple functions in these tissues but with yet unknown importance.

Circulating total and acylated ghrelin levels are reduced in obesity (22-24) and metabolic syndrome $(25,26)$, and among obese subjects, the total plasma ghrelin concentrations have been reported to be lower in insulin-resistant patients (27), but the results have been variable and conflicting in different studies (28-30). The lower levels of ghrelin were associated with higher prevalence of the metabolic syndrome, with progressively lower levels as the number of components of the metabolic syndrome increased $(31,32)$, and others showed associations between acylated ghrelin and serum insulin and insulin resistance (33). Generally, plasma ghrelin is inversely associated with insulin concentrations and measures of adiposity and directly with insulin sensitivity and HDL cholesterol concentrations (34-37).

So far, only total plasma ghrelin levels have been investigated in diet-induced and combined exercise/diet weight loss studies. Previous studies have shown either an increase in ghrelin concentrations in obese subjects $(30,38-43)$ or no change in overweight healthy adults (44) or obese children $(45,46)$. However, during weight maintenance after weight loss, the ghrelin levels decreased back to the levels before weight loss (47). Even an initial decrease along with weight loss and a subsequent increase in plasma ghrelin has been reported (48).

Effect of exercise on circulating ghrelin levels has been inconsistent (49). In trials investigating overweight or obese subjects, total ghrelin was unaffected by shortterm exercise, whereas acylated ghrelin increased (50). During a long-term exercise intervention aiming at exercise-induced weight loss, total plasma ghrelin increased $(51,52)$, whereas acylated ghrelin remained unchanged (52).

The aims of our study were 1) to examine the expression of ghrelin and ghrelin receptors in peripheral blood mononuclear cells (PBMCs), 2) to evaluate the clinical and genetic determinants of ghrelin expression in PBMCs, 3) to evaluate the associations with expression of pro-inflammatory cytokines, 4) to evaluate the clinical and genetic determinants of plasma ghrelin concentrations and 5) to test the effects of weight reduction or exercise intervention on the plasma ghrelin levels in subjects with impaired fasting glycaemia or impaired glucose tolerance (IGT) and the metabolic syndrome. Furthermore, PBMCs from venous blood samples are the most accessible tissue for analysis of gene expression and least demanding for the patients compared with biopsies of other tissues.

\section{Materials and methods}

\section{Subjects and study design}

Originally, the Genobin study included 75 overweight or obese (BMI $28-40 \mathrm{~kg} / \mathrm{m}^{2}$ ) men and women aged 40 to 70 years with impaired fasting glucose (IFG) or IGT and at least two other features of metabolic syndrome according to the Adult Treatment Panel III criteria as modified by the AHA (53): waist circumference $>102 \mathrm{~cm}$ (males) $/>88 \mathrm{~cm}$ (females), fasting serum triacylglycerol concentration $>1.7 \mathrm{mmol} / \mathrm{l}$, fasting serum HDL cholesterol $<1.0 \mathrm{mmol} / \mathrm{l}$ (males)/ $<1.3 \mathrm{mmol} / \mathrm{l}$ (females) and blood pressure $>130$ / $80 \mathrm{mmHg}$. IFG was defined as fasting plasma glucose concentration 5.6-7.0 mmol/l, and IGT was defined as 2-h plasma glucose concentration $7.8-11.0 \mathrm{mmol} / \mathrm{l}$ and fasting plasma glucose $<7.1 \mathrm{mmol} / \mathrm{l}$. The study subjects were recruited through newspaper advertisement and additionally subjects from previous studies, who indicated interest in future studies were contacted. The subjects were then randomized to one of the following groups: weight reduction (WR, $n=28$ ), aerobic exercise training $(\mathrm{AE}, n=15)$, resistance exercise training (RE, $n=14$ ) or control group (CG, $n=18)$. The subjects were randomized at the Department of Clinical Nutrition (WR, $n=6$ and CG, $n=7)$ and at Kuopio Research Institute of Exercise Medicine (WR, $n=22$; CG, $n=11$; AE, $n=15$ and RE, $n=14$ ). The subjects were matched for age, sex and the status of glucose metabolism. In addition, 11 normal weight persons (mean age $48 \pm 9$ years, mean BMI $23.7 \pm 1.9 \mathrm{~kg} / \mathrm{m}^{2}$ ) were recruited. The intervention was performed in accordance with the standards of the Helsinki Declaration. The Ethics Committee of the District Hospital Region of Northern Savo and Kuopio University Hospital approved the study plan, and all participants gave written informed consent.

\section{Interventions}

Weight reduction programme The duration of the intervention varied between 32 and 38 weeks (mean duration $33 \pm 1$ weeks). The WR group had a 12 -week intensive weight reduction period based on individual counselling by a clinical nutritionist (53). Adjustments on subjects' diet were made in order to encourage a higher intake of fruits and vegetables and up to $30 \%$ of total fat intake resulting in a mean deficit in caloric 
intake of about $500 \mathrm{~kJ} / \mathrm{d}$. The minimum aim for the following study weeks 12-33 was to maintain the weight loss achieved based on the same dietary prescription. Subjects were asked to keep their habitual level of physical exercise unchanged.

Exercise training In exercise training groups, the individualized and progressive training programmes were prescribed based on measured cardiorespiratory fitness level and muscular strength levels. Isometric muscular strength levels for lower extremity and handgrip were measured, and cycle ergometer test measuring $\mathrm{VO}_{2}$ max and balance test were performed at baseline and at the end of the intervention period in both training groups. In addition, the subjects were asked to fill in physical activity diaries during the entire intervention.

The subjects in the AE group had first a 4- to 8-week accustoming period. During this phase, the subjects were asked to exercise twice or thrice per week for $30 \mathrm{~min}$ at low intensity per session. After that, training frequency was increased to a minimum of four times per week for at least $30 \mathrm{~min}$ per session and at $55-65 \%$ of the maximum level. The participants had follow-up visits once a month throughout the study.

The RE group had first a 2 week accustoming period in order to get used to the muscle training equipments. Thereafter, the muscle strength was measured by using five repetition maximum (RM) tests. Based on these measurements, training programmes were prescribed. During the first month, participants were given instructions to perform two training sessions per week at $60 \%$ load of 1 -RM, $1 \times 16$ repetitions. The programme for the next three months was planned to include three to four training sessions per week at $70 \%$ of $1-\mathrm{RM}, 1 \times 12$ repetitions. The last months included three to four training sessions per week at 70\% 1-RM, $2 \times 10-12$ repetitions. The muscle strength was measured by 5-RM tests before every modification in the programme and at the end of the programme. The participants also had follow-up visits once a month and were advised to keep their diet habits unchanged during the whole intervention period.

Control group The subjects in the control group were advised to continue their normal lifestyle during the study and to keep their diet and exercise habits unchanged.

\section{Medical examinations and measurements}

At screening, the health status and medical history of the subjects were examined by an interview and laboratory examinations were carried out (53). All subjects kept a 4-day food record at baseline and at the end of the study (week 32). At baseline and at the end of the intervention period, a 2-h oral glucose tolerance test (OGTT) was performed with $75 \boldsymbol{g}$ glucose per os (glucosum anhydricum, Oriola Oy, Espoo, Finland). Blood samples for plasma glucose and serum insulin concentrations were drawn at 0,30 and $120 \mathrm{~min}$. The frequently sampled intravenous glucose tolerance test was performed according to the minimal model method, as previously described (54). Insulin sensitivity index $\left(\mathrm{S}_{\mathrm{I}}\right)$, glucose effectiveness $\left(\mathrm{S}_{\mathrm{G}}\right)$ and acute phase insulin response to glucose (AIR) were calculated by the MINMOD Millennium software (Pasadena, CA, USA) (55). The subjects also underwent blood pressure, anthropometric and biochemical measurements, as described in detail elsewhere (53). These measurements were also performed at week 12 .

\section{Hormone assays}

Blood samples were collected in pre-chilled tubes containing EDTA and immediately centrifuged. Plasma was stored at $-80{ }^{\circ} \mathrm{C}$ until assayed. Overnight fasting plasma levels of ghrelin, which correlate well with 24-h integrated area under the curve values of ghrelin $(34,56)$, were measured by RIA using a commercially available kit (Linco Research Inc., St Charles, MO, USA). This assay detects both acylated and deacylated ghrelin. The lower and upper detection limits were 187.5 and $6000 \mathrm{pg} / \mathrm{ml}$ respectively. The intra- and inter-assay coefficients of variance (CV) were 8.7 and $14.5 \%$ respectively. All samples were run in duplicates in a single assay. Serum leptin was analysed by a commercially available RIA kit (Linco Research Inc). The intraand inter-assay CV were 12.2 and $13.0 \%$ respectively. Insulin was determined by a chemiluminescence sandwich method using an ACS automated system (Bayer A/S). The intra- and inter-assay CV were 7.7 and $9.0 \%$ respectively. Plasma tumour necrosis factor- $\alpha$ (TNF- $\alpha$ ), interleukin (IL)-6 and IL1- $\beta$ concentrations were measured by solid phase ELISA (Quantikine, R\&D Systems, Minneapolis, MN, USA). The intra- and interassay CV were 6.1 and $7.7 \%, 5.9$ and $10.9 \%$, and 9.7 and $9.7 \%$ respectively. High-sensitivity C-reactive protein (hsCRP) was determined by Immage Immunochemistry System (Immulite 2000 DPC, Los Angeles, LA, USA) with an analytical range of $0.1-250 \mathrm{mg} / \mathrm{l}$ and a sensitivity of $0.2 \mathrm{mg} / \mathrm{l}$.

\section{Isolation of PBMCs}

PBMCs were isolated from anticoagulated peripheral blood by density centrifugation using Lymphoprep reagent (Axis-Shield, Oslo Norway) according to manufacturer's instructions. The cells were washed with PBS (Invitrogen) and thereafter stored in RNAlater according to the manufacturer's instructions (Ambion, Austin, TX, USA) and stored in $-80^{\circ} \mathrm{C}$ until used for RNA isolation. Altogether 56 samples for all three time points were available for 24 subjects of the WR group, 9 subjects of the RE group, 13 subjects of the AE group and 10 subjects of the CG group. Only subjects for whom PBMC samples were available at all three time points were included in the analysis. 


\section{RNA isolation}

Total RNA was isolated using RNeasy Mini Kit columns according to the manufacturer's instructions (Qiagen). The RNA concentration and the $A_{260} / A_{280}$ ratio was measured using a NanoDrop spectrophotometer (NanoDrop Technologies, Wilmington DE, USA), an acceptable ratio being 1.9-2.1. Integrity of the RNA was assessed using agarose gel electrophoresis.

\section{Real-time PCR analysis of gene expression}

RNA was reverse transcribed into cDNA using HighCapacity cDNA Archive Kit (Applied Biosystems, Foster City, CA, USA). The real-time PCR analyses were performed with TaqMan chemistry with ready-made assays according to the manufacturer's instructions (Applied Biosystems). The samples were analysed in triplets with an Applied Biosystems 7500 Real-Time PCR System (Foster City, CA, USA). We used absolute quantification, the values for the amount of unknown samples were extrapolated from a standard curve. On each plate, a standard curve with points of $0.5,1.5,6$, 18 and $36 \mathrm{ng}$ and a calibrator of $6 \mathrm{ng}$ mRNA equivalent was used. The cDNA pool for the standard curve was created by combining cDNA from a representative number of subjects of all three time points. Quantities on each plate were first corrected by the calibrator on the plate. The quantity values were finally normalized to the expression of the endogenous control glyceraldehyde-3-phosphate dehydrogenase.

\section{Genotype analysis}

Genotyping was performed by PCR-based restriction fragment length polymorphism analysis, as described elsewhere (10). A subset of randomly selected samples was repeated to ensure correctness.

\section{Statistical analysis}

The association between the plasma ghrelin concentrations at baseline and the variables studied was assessed using linear regression analysis. With ghrelin as the dependent variable, sex, age, BMI and the variable studied were entered into the multivariate models as independent variables. Linear regression analysis was also used to test associations between the gene expression of ghrelin and GHSR $1 \mathrm{~b}$ and several cytokines in PBMCs at baseline. Ghrelin expression and sex, age and BMI were entered as covariates in a multivariate model.

To test the difference of plasma ghrelin concentrations and ghrelin expression in PBMCs between men and women, an independent samples $t$-test was used. Univariate ANOVA was applied to test the difference in plasma ghrelin levels, ghrelin and GHSR $1 \mathrm{~b}$ expression in PBMCs at baseline between normal weight and overweight/obese subjects with features of metabolic syndrome with age and sex included in the model. Linear mixed models analysis was performed to test the relationship between plasma ghrelin concentrations or ghrelin expression in PBMCs and relevant variables longitudinally over the whole study period. Repeated measures ANOVA was used for testing the interaction between plasma ghrelin concentrations and the study groups during the study period (baseline, weeks 12 and 33). Differences between the groups at different time points and between the different time points for the groups separately were tested with estimated marginal means applying Bonferroni correction. Repeated measures ANOVA was also used to test the differences among the SNP genotypes in gene expression of ghrelin during the study. Covariates study group, sex, age and $\mathrm{BMI}$ at baseline were tested and removed from the model when not significantly contributing. $P$ values are for trend across all three genotype groups and Bonferroni correction was applied for post hoc pairwise comparisons. Correlations between changes in the plasma ghrelin levels with other measurements were performed using Pearson's correlation for normally distributed variables and Spearman correlation when variables were not normally distributed even after logarithmic transformation. Homogeneity of variances was tested using Levene's test. To normalize the skewed distributions, logarithmic transformations or reciprocal and square root transformations were applied when needed. A $P$ value $<0.05$ was considered significant. All analyses were performed using SPSS software version 14.0 for Windows (SPSS Inc., Chicago, IL, USA).

\section{Results}

All study subjects were overweight or obese (mean BMI $32.9 \pm 2.8 \mathrm{~kg} / \mathrm{m}^{2}$ ) with an average age of $60 \pm 7$ years at baseline. General and dietary characteristics at baseline and at the end of the study are presented separately for the three intervention groups and the control group (Table 1).

\section{Ghrelin and GHSR expression in PBMCs}

Both ghrelin and GHSR 1b mRNA were expressed in PBMCs of all study subjects, whereas GHSR 1a mRNA expression could not be detected. The mean ghrelin expression in PBMCs at baseline was 107.9 in arbitrary units (AU; range 47.5-240.3), with mean $C_{t}$ values of 31.9 (range 31.1-33.3). The mean values for men and women were $99.6 \pm 39.5$ and $116.9 \pm 45.8 \mathrm{AU}$ at baseline respectively $(P=0.157)$. At baseline, the intervention groups displayed different levels of ghrelin expression $(P=0.018)$. During the intervention, however, the groups did not differ from each other regarding ghrelin expression in PBMCs in a model adjusted for baseline ghrelin expression (ghrelin 


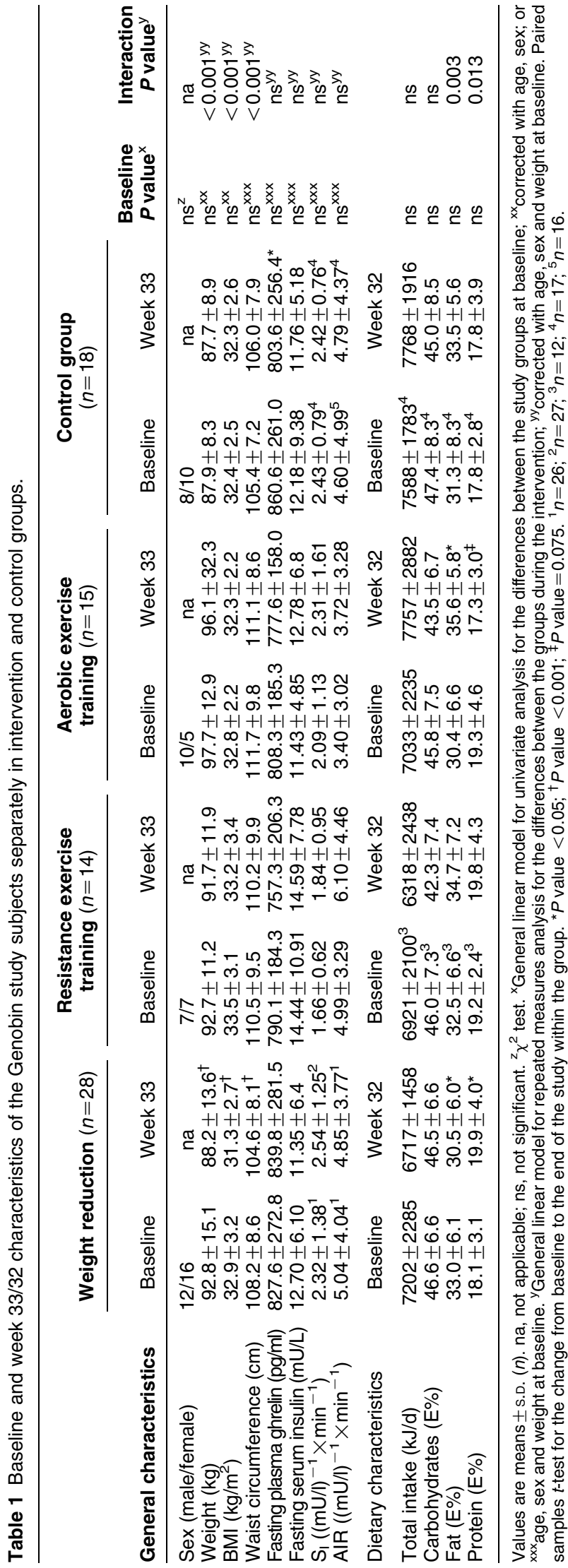

expression $\times$ group interaction $P=0.778$; group effect $P=0.459$ ). Therefore, all intervention groups were analysed together. Ghrelin expression did not differ between overweight/obese study subjects and normal weight persons $(P=0.733$, adjusted for age and sex; mean ghrelin expression of normal weight persons 116.4 AU, range 55.3-210.3 AU).

The mean GHSR $1 \mathrm{~b}$ expression in PBMCs at baseline was 94.8 AU (range 5.6-619.3) with mean $C_{\mathrm{t}}$ values of 31.0 (range 27.2-33.7) and there was no significant difference between men and women $(P=0.613$; mean $78.2 \pm 62.6 \mathrm{AU}$ and $112.7 \pm 138.1 \mathrm{AU}$ respectively).

Ghrelin and GHSR $1 \mathrm{~b}$ expressions were positively associated at baseline $(P<0.001, \beta=0.463)$. When the data were analysed longitudinally, the association was no longer statistically significant $(P=0.111)$.

\section{Association with plasma ghrelin concentrations and anthropometric measurements No significant correlation between plasma ghrelin concentrations and ghrelin mRNA expression in PBMCs was observed at baseline (Table 1$)$ nor longitudinally $(P=0.427)$. Measures of adiposity, waist circumference, weight and BMI were not associated with ghrelin mRNA expression in PBMCs longitudinally $(P=0.496$, $P=0.756, P=0.831$ respectively).}

Association with inflammatory markers The ghrelin mRNA expression in PBMCs had a significant positive association with TNF- $\alpha$ expression at baseline $(P=0.010, \beta=0.353)$. The longitudinal analysis showed a significant positive association between ghrelin and TNF- $\alpha$ expressions during the time course of the study independently of BMI, sex or age $(P<0.001$; Fig. 1A). IL-1 $\beta$ expression in PBMCs did not associate with ghrelin expression in PBMCs at baseline $(P=0.787, \beta=0.038)$. However, longitudinal analyses showed a significant positive association during the study independently of BMI, sex and age $(P<0.001$; Fig. 1B). In addition, $\Delta \%$ IL1b showed positive correlation to $\Delta \%$ ghrelin expression $(P<0.001, r=0.503)$. No association between IL- 6 and ghrelin expressions in PBMCs was seen at baseline $(P=0.663, \beta=0.062)$, but the association was significant longitudinally $(P=0.026$, Fig. $1 C)$.

\section{Effect of ghrelin gene variations on ghrelin expression in PBMCs}

The observed allele and genotype frequencies in all genotyped SNPs were in Hardy-Weinberg equilibrium and are similar to those reported earlier in the population of the Finnish Diabetes Prevention Study (10). At baseline, there were no significant differences between the genotypes of the two most common polymorphisms $-604 \mathrm{G} / \mathrm{A}$ and $-501 \mathrm{~A} / \mathrm{C}$ in clinical and anthropometric characteristics of the subjects (data not shown). However, significant differences were 


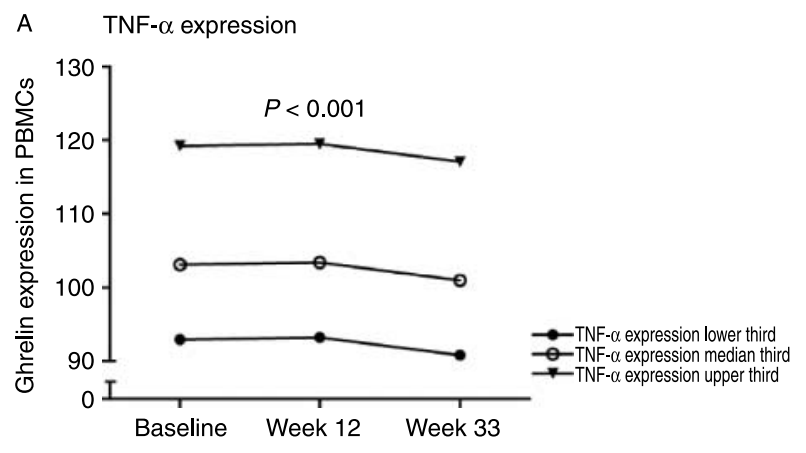

B IL-1 $\beta$ expression

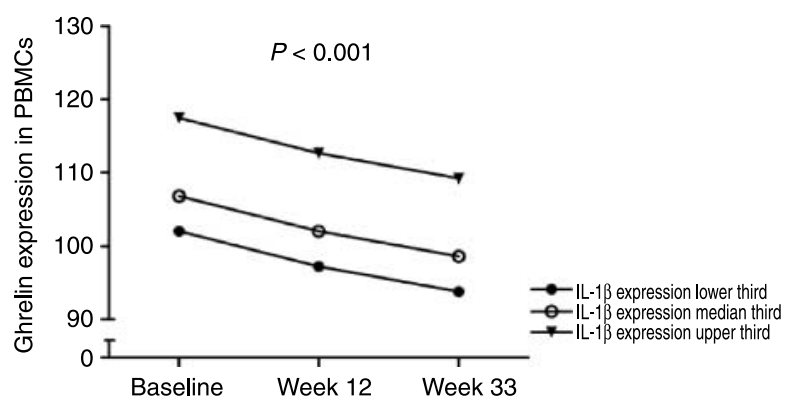

C IL-6 expression

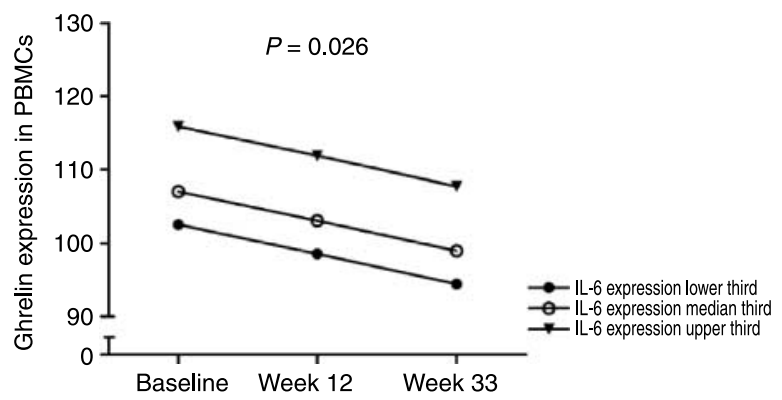

Figure 1 (A) The ghrelin mRNA expression in PBMCs according to TNF- $\alpha$ mRNA expression tertiles at baseline, weeks 12 and 33 . Values are estimated marginal means calculated at different mean values for lower ( 0 ; 74.6; range 45.9-87.4), median $(0 ; 97.2$; range 87.7-105.4) and upper third ( $\boldsymbol{\nabla}$; 132.7; range 105.4-197.2) of TNF- $\alpha$ expression from the linear mixed models analysis. (B) The ghrelin mRNA expression in PBMCs according to IL-1 $\beta$ expression tertiles at baseline, weeks 12 and 33 . Values are estimated marginal means calculated at different mean values for lower

( $; 50.7$; range 22.6-70.2), median ( 0 ; 89.5; range 72.0-114.3) and upper third ( $\boldsymbol{\nabla} ; 175.2$; range 114.6-615.0) of IL-1 $\beta$ expression from the linear mixed models analysis. (C) The ghrelin mRNA expression in PBMCs according to IL- 6 expression tertiles at baseline, week 12 and week 33 . Values are estimated marginal means calculated at different mean values for lower $(0 ; 49.8$; range 12.5-70.7), median $(\bigcirc ; 91.1$; range 70.9-119.4) and upper third ( $\mathbf{\nabla} ; 171.4$; range 121.4-308.0) of IL-6 expression from the linear mixed models analysis.

observed in the ghrelin mRNA expression in PBMCs in relation to these two polymorphisms. Subjects with the AA genotype of the $-604 \mathrm{G} / \mathrm{A}$ polymorphism had lower ghrelin expression in PBMCs than subjects with GG $(P=0.003)$ or GA genotype $(P=0.060$; Fig. $2 A)$.
Similarly, subjects with the CC genotype of the $-501 \mathrm{~A} / \mathrm{C}$ polymorphism had lower ghrelin expression in PBMCs than subjects with the AA genotype $(P=0.009)$ (Fig. 2B). BMI at baseline, sex, age or study group did not significantly contribute to the different expression levels between the genotypes of either of the polymorphisms. Polymorphisms in the ghrelin gene were not, however, associated with plasma ghrelin concentration (data not shown).

\section{Plasma ghrelin concentrations at baseline}

At baseline, the mean fasting plasma ghrelin concentration in the whole study population $(n=75)$ was
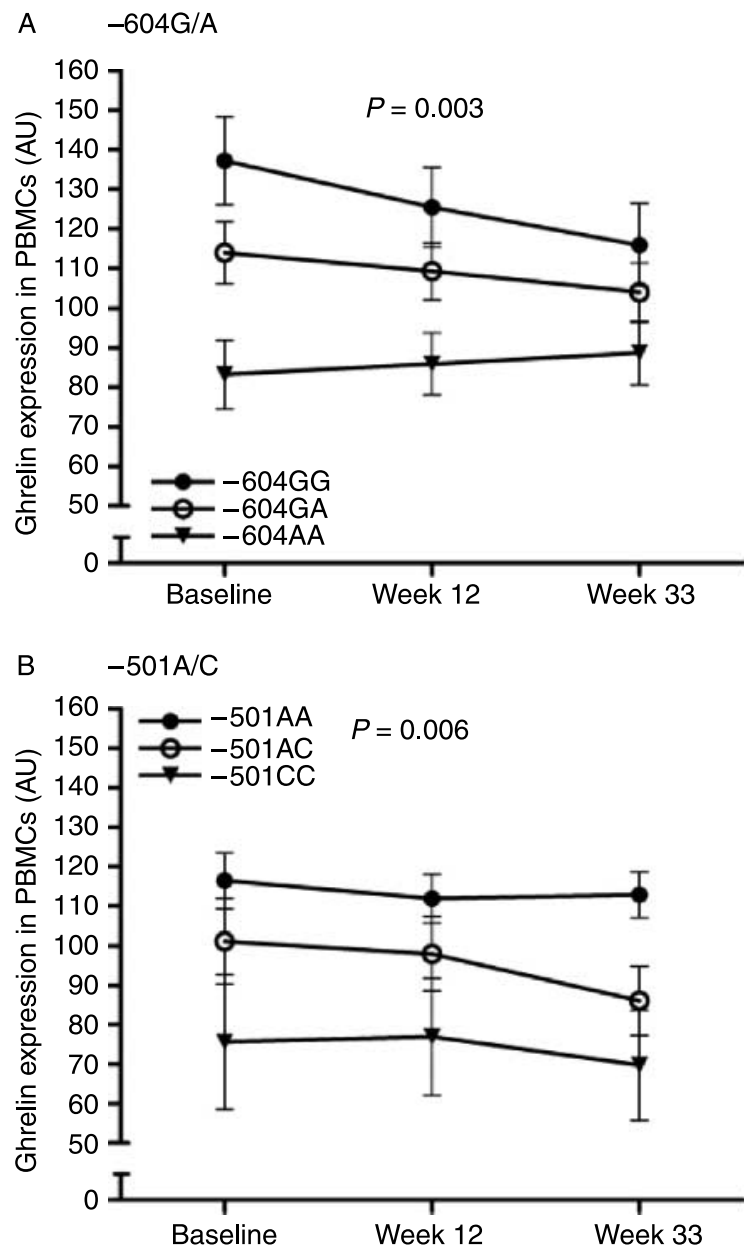

Figure 2 The ghrelin mRNA expression in PBMCs in all study subjects at three time points of the study according to the (A) $-604 \mathrm{G} / \mathrm{A}$ and the $(\mathrm{B})-501 \mathrm{~A} / \mathrm{C}$ polymorphism of the ghrelin gene. Values are estimated marginal means \pm S.E.M. calculated from repeated measures ANOVA. (A) Subjects with -604GG genotype (O; $n=12) ;-604 \mathrm{GA}$ genotype $(O ; n=24) ;-604 \mathrm{AA}$ genotype $(\boldsymbol{\nabla} ; n=20)$. Pairwise comparisons: $\mathrm{GG}$ versus $\mathrm{GA}, P=0.397 ; \mathrm{GG}$ versus $A A, P=0.003$; GA versus $A A, P=0.060$. (B) Subjects with $-501 \mathrm{AA}$ genotype (O;n=35); - 501AC genotype $(\bigcirc ; n=15)$; $-501 C C$ genotype $(\boldsymbol{\nabla} ; n=6)$. Pairwise comparisons: AA versus $A C$, $P=0.188$; AA versus CC, $P=0.009 ;$ AC versus $C C, P=0.332$. 
$825 \mathrm{pg} / \mathrm{ml}$ (range $451-1468 \mathrm{pg} / \mathrm{ml}$ ). The mean values $( \pm$ s.D. ) for men and women were $795 \pm 231$ and $854 \pm$ $241 \mathrm{pg} / \mathrm{ml}$ respectively $(P=0.283)$. Plasma ghrelin levels in overweight/obese study subjects were significantly lower than those in normal weight persons $(P=0.005$, adjusted for age and sex; mean fasting plasma ghrelin concentration of normal weight persons $1056 \mathrm{pg} / \mathrm{ml}$, range $622-1510 \mathrm{pg} / \mathrm{ml}$ ).

Associations between various characteristics of the study subjects and plasma ghrelin levels are shown in Table 2. Fasting serum insulin concentrations, insulin concentrations during an OGTT, $\mathrm{S}_{\mathrm{I}}$ and HDL cholesterol were significant independent predictors of ghrelin concentration at baseline (Table 2). A trend for a negative association between plasma ghrelin levels and AIR was seen (Table 2). Weight, BMI and waist circumference were not correlated with plasma ghrelin concentrations in overweight/obese study subjects at baseline. Further, there was no correlation between fasting serum leptin and plasma ghrelin levels, or with circulating cytokines and hsCRP (Table 2).

\section{Plasma ghrelin concentrations during interventions}

AII study subjects Fasting serum insulin was a significant predictor of fasting plasma ghrelin concentrations $(P=0.024)$ when analysed longitudinally.

Table 2 Correlations between plasma ghrelin concentrations and various characteristics of the subjects at baseline.

\begin{tabular}{|c|c|c|}
\hline & $\beta$ & $P$ value $^{\mathrm{a}}$ \\
\hline Weight (kg) & -0.048 & $0.732^{\mathrm{b}}$ \\
\hline $\operatorname{BMI}\left(\mathrm{kg} / \mathrm{m}^{2}\right)$ & -0.109 & $0.376^{\mathrm{b}}$ \\
\hline Waist circumference $(\mathrm{cm})$ & -0.279 & 0.217 \\
\hline \multicolumn{3}{|c|}{ Plasma glucose (mmol/l), OGTT } \\
\hline $0 \mathrm{~min}$ & -0.081 & 0.512 \\
\hline $30 \mathrm{~min}$ & -0.035 & 0.778 \\
\hline $120 \min$ & -0.011 & 0.929 \\
\hline \multicolumn{3}{|l|}{ Serum insulin (mU/l), OGTT } \\
\hline $0 \mathrm{~min}$ & -0.483 & $<0.001$ \\
\hline $30 \mathrm{~min}$ & -0.368 & 0.003 \\
\hline $120 \mathrm{~min}$ & -0.457 & $<0.001$ \\
\hline $\mathrm{S}_{\mathrm{I}}\left((\mathrm{mU} / \mathrm{l})^{-1} \times \mathrm{min}^{-1}\right)$ & 0.343 & 0.006 \\
\hline $\operatorname{AIR}\left((\mathrm{mU} / \mathrm{l})^{-1} \times \min ^{-1}\right)$ & -0.236 & 0.068 \\
\hline Total cholesterol (mmol//) & 0.063 & 0.595 \\
\hline HDL cholesterol (mmol/l/) & 0.300 & 0.016 \\
\hline LDL cholesterol (mmol/l) & -0.030 & 0.801 \\
\hline VLDL cholesterol (mmol//) & 0.113 & 0.341 \\
\hline Triglycerides $(\mathrm{mmol} / \mathrm{l})$ & 0.051 & 0.665 \\
\hline Leptin (ng/ml) & -0.192 & 0.417 \\
\hline TNF- $\alpha(\mathrm{pg} / \mathrm{ml})$ & 0.092 & 0.208 \\
\hline IL-6 (pg/ml) & -0.091 & 0.467 \\
\hline IL-1 $\beta(\mathrm{pg} / \mathrm{ml})$ & 0.066 & 0.578 \\
\hline hsCRP (mg/l) & 0.092 & 0.455 \\
\hline $\begin{array}{l}\text { Ghrelin mRNA expression in } \\
\text { PBMCs (AU) }\end{array}$ & -0.150 & 0.882 \\
\hline
\end{tabular}

$P$ values and standardized regression coefficients $\beta$ obtained from linear regression analyses adjusted for ${ }^{(a)}$ age, sex and BMI and ${ }^{(b)}$ age and sex. $S_{\text {, }}$, insulin sensitivity; AIR, acute insulin response; PBMCs, peripheral blood mononuclear cells; AU, arbitrary units.
However, when weight, BMI or waist circumference was added separately as a covariate into the model, these measures of adiposity significantly contributed to the plasma ghrelin concentration $(P=0.050, P=0.025$, $P=0.023$ respectively) and the fasting insulin concentration was no longer significant $(P=0.075-0.128)$. In fact, weight, BMI and waist circumference were strongly associated with plasma ghrelin longitudinally $(P=0.013$ for weight, 0.004 for BMI, 0.005 for waist, Fig. 3B). When substituting $S_{\mathrm{I}}$ for fasting insulin in the analyses, $S_{\mathrm{I}}$ did not significantly contribute to the ghrelin concentrations. However, when AIR was tested, it significantly influenced the fasting plasma ghrelin concentrations over the study period ( $P=0.001$, Fig. 3A), even after adjusting for the effect of weight, BMI, waist circumference and $S_{I}$.

An inverse relationship between the relative changes in weight ( $\% \Delta$ weight $)$ and plasma ghrelin $(\% \Delta$ ghrelin $)$ from baseline to week $33(P=0.010, \beta=-0.294)$ was seen in all study subjects. $\% \Delta$ ghrelin did not correlate with the relative change in fasting insulin, $S_{\text {I }}$ or AIR (data not shown).

Interaction terms with regard to different study groups for above-mentioned variables were tested in all models and were not significant; therefore, the longitudinal relationships were analysed in all study subjects.

Weight reduction and plasma ghrelin concentrations Body weight, as well as BMI and waist circumference, decreased in the WR group during the 33-week intervention period, but did not change significantly in the exercise and control groups (Table 1). When subjects from the WR group $(n=28)$ were compared with those from the control group $(n=18)$, the interaction term for plasma ghrelin $\times$ group indicated a trend for difference $(P=0.067)$ and the plasma ghrelin concentrations differed significantly between the groups at week 12 $(P=0.042)$ and $33(P=0.024)$ with higher concentrations in the WR group (Fig. 4A). However, the plasma ghrelin concentrations in subjects in the WR group did not significantly increase from baseline to week 12 or 33 , whereas in the control group ghrelin concentrations decreased from baseline to weeks $12(P=0.067)$ and 33 $(P=0.050 ;$ Fig. 4A). To study the effect of weight reduction in more detail, the weight reduction group was divided into those who lost 5\% or more of their body weight $(n=11)$ and those who lost less than $5 \%(n=17)$ (53). The plasma ghrelin levels of subjects who lost $5 \%$ or more of their body weight showed an increasing trend over the study duration (baseline, $787 \pm 167 \mathrm{pg} / \mathrm{ml}$; week 12, $816 \pm 193 \mathrm{pg} / \mathrm{ml}$; week 33, $811 \pm 149 \mathrm{pg} / \mathrm{ml}$; Fig. 4B), but was not statistically significant in spite of their success in the intervention.

As shown in Table 1, fat intake (E\%) decreased and protein intake $(\mathrm{E} \%)$ increased significantly from baseline to the end of the study in the weight reduction group, whereas the carbohydrate intake $(\mathrm{E} \%)$ remained stable. However, correlation analysis between $\% \Delta$ ghrelin and changes in fat intake and protein intake from baseline 
A Acute insulin response

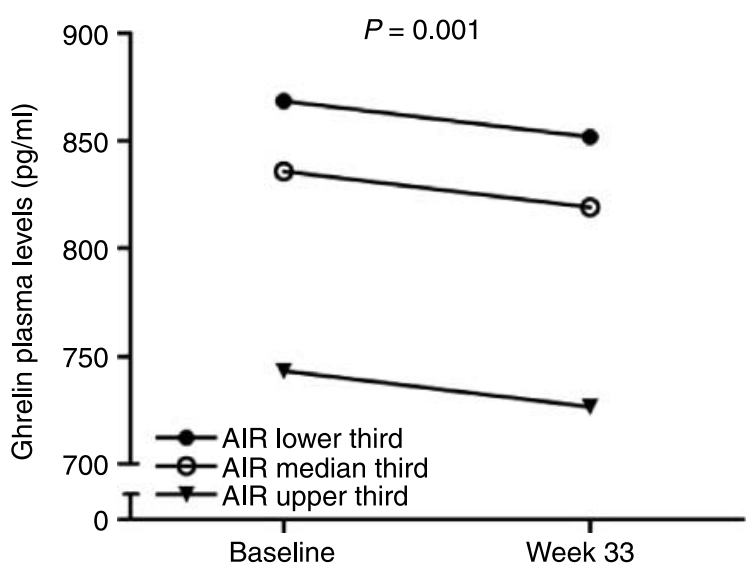

B Waist circumference

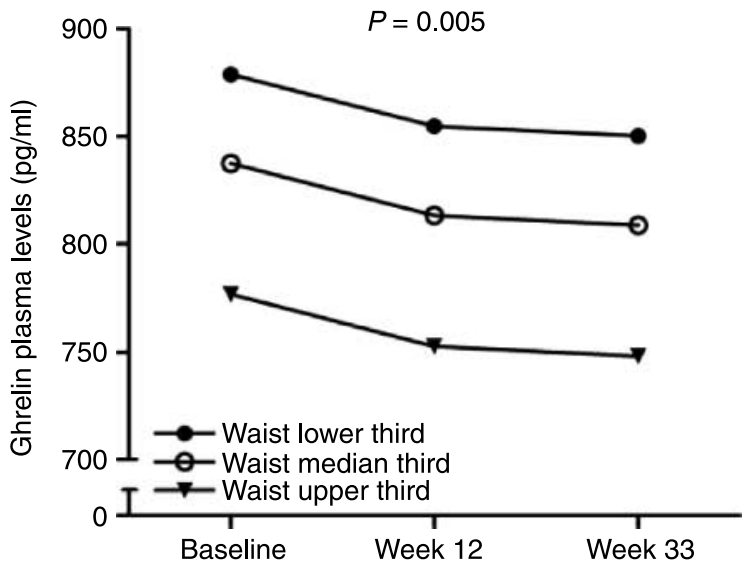

Figure 3 (A) Fasting plasma ghrelin levels according to acute insulin response (AIR) tertiles at baseline and week 33 . Values are estimated marginal means calculated at different mean values for lower $(\odot ; 1.56$; range $0.08-2.48)$, median $(\bigcirc ; 3.55$; range 2.54-4.80) and upper third ( $\mathbf{\nabla} ; 9.17$; range 4.89-19.88) of AIR from the linear mixed models analysis. (B) Fasting plasma ghrelin levels according to waist circumference tertiles at baseline, week 12 and week 33. Values are estimated marginal means calculated at different mean values for lower $(\bullet ; 98.5$; range 87.2-102.2), median $(O ; 106.2$; range $102.3-110.6)$ and upper third $(\mathbf{\nabla} ; 117.6$; range 110.7-135.5) of waist circumference from the linear mixed models analysis.

to the end of the study showed no associations (data not shown).

\section{Discussion}

In the first part of our study, we showed that ghrelin mRNA is variably expressed in PBMCs of subjects with metabolic syndrome. Previous reports have shown ghrelin expression in immune cells ( $\mathrm{T}$ cells, B cells and neutrophils) from normal subjects $(18,19)$, but with great individual variations in the expression levels (18). Ghrelin expression in PBMCs was not influenced by the
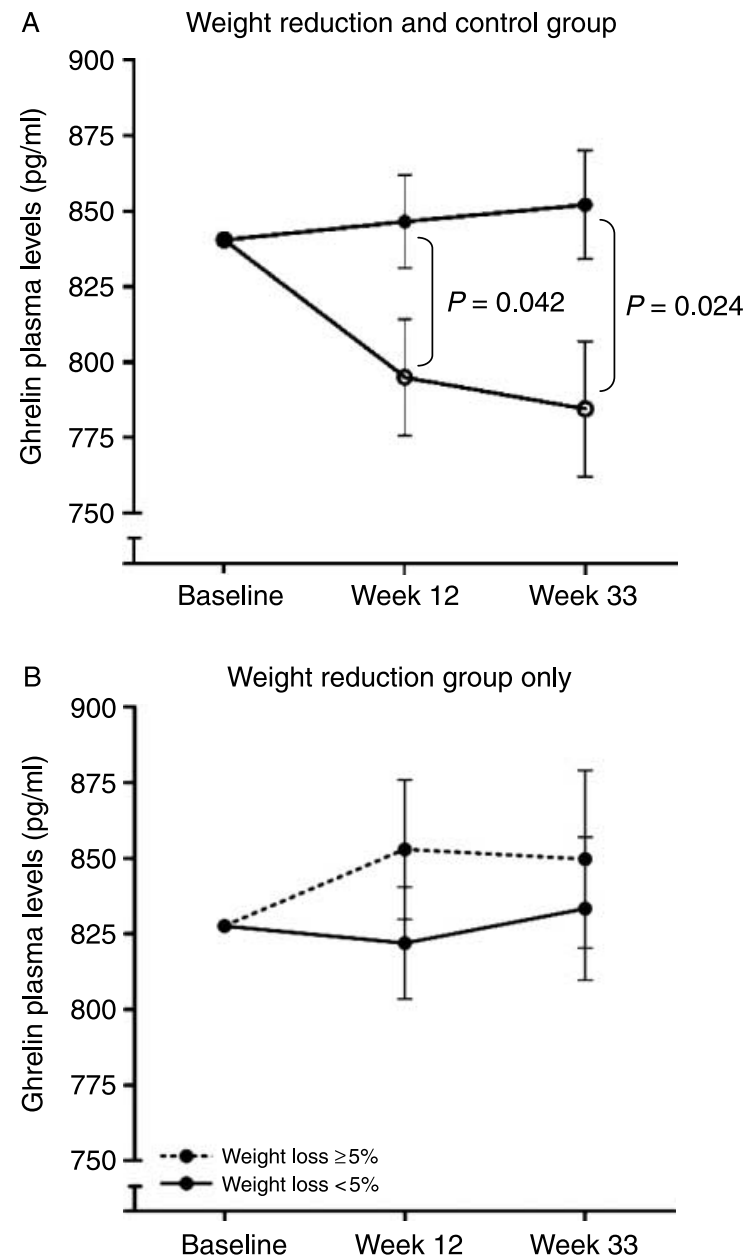

Figure 4 (A) Plasma ghrelin in the weight reduction $(O ; n=28)$ and control $(O ; n=18)$ groups. Repeated measures ANOVA with the baseline plasma ghrelin levels as covariate. Values are estimated marginal means \pm S.E.M. Interaction term plasma ghrelin $\times$ group $P=0.067$. (B) Plasma ghrelin in the weight reduction group divided according to degree of weight loss. Dashed line, weight loss $\geq 5 \%$ $(n=11)$; solid line, weight loss $<5 \%(n=17)$.

different interventions prescribed to the study subjects, nor was a difference between overweight/obese compared with normal weight persons evident. Furthermore, the ghrelin expression was not influenced by measures of adiposity and did not correlate with the plasma ghrelin levels. We found that polymorphisms of the ghrelin promoter region, the $-604 \mathrm{G} / \mathrm{A}$ and $-501 \mathrm{~A} / \mathrm{C}$ variants, markedly modify the ghrelin gene expression in PBMCs, which may explain the individual variation of ghrelin expression in PBMCs in part. Differences in ghrelin gene expression in PBMCs according to SNPs in the ghrelin gene are one factor contributing to the variation, in addition to the normal extent of inter-individual variation, which has been shown in healthy humans (57) and is supposedly larger in a group of subjects with inhomogeneous metabolic disturbances. 
Interestingly, GHSR 1b mRNA was also expressed in PBMCs, whereas GHSR 1a mRNA could not be detected. We found a positive correlation between ghrelin and TNF- $\alpha$, IL- $1 \beta$ and IL- 6 expressions in PBMCs over the whole study period and a positive correlation between changes in the expression of ghrelin and IL-1 $\beta$ from baseline to the end of the study. A previous study has shown that ghrelin treatment inhibited production of proinflammatory cytokines (IL-1 $\beta$, IL- 6 and TNF- $\alpha$ ) by PBMCs via a GHSR-specific pathway (19). It was further reported that ghrelin inhibited IL- 6 and TNF- $\alpha$ mRNA expressions in primary human $\mathrm{T}$ cells, which supports a role for ghrelin in the transcriptional regulation of inflammatory cytokine expression (19). Anti-inflammatory effects of ghrelin mediated through activation of GHSR 1a in human endothelial cells have also been reported (58).

On the contrary, in our study, ghrelin expression directly correlated with TNF- $\alpha$, IL- $1 \beta$ and IL- 6 expressions in PBMCs. However, only GHSR type $1 \mathrm{~b}$ was expressed in PBMC samples, whereas the expression of GHSR 1a was too low to be detected. Recently, GHSR $1 \mathrm{~b}$ has been described as a dominant-negative mutant of GHSR 1a, resulting in attenuation of its constitutive signalling (59). The inhibition of pro-inflammatory cytokines in PBMCs has been shown to be GHSR 1a specific $(19,58)$. We can hypothesize that in our study, higher expression of ghrelin led to a higher expression of pro-inflammatory cytokines due to the absence of GHSR 1a expression and the concomitant attenuation of GHSR 1a action.

Genetic variations in the ghrelin gene were not associated with the plasma ghrelin concentrations in our study. A limitation in the present study is the sample size, which is rather small for genetic association studies and thus results should be interpreted with caution.

Plasma ghrelin levels correlated negatively with fasting serum insulin and insulin levels during the OGTT and positively with $S_{I}$ and serum HDL cholesterol concentration cross-sectionally, which is supported by previous literature $(22,27,34,36,37)$. However, in our longitudinal data, measures of central obesity seem to be more important contributing factors, explaining low ghrelin concentrations in persons with the metabolic syndrome, than insulin or insulin sensitivity. Interestingly, low AIR was also associated with high ghrelin concentrations longitudinally, suggesting that firstphase insulin secretion per se could influence ghrelin secretion. However, it was suggested previously that early insulin response does not affect plasma ghrelin (60). Numerous studies have been carried out to unravel the ambiguous relationship between insulin and ghrelin. It has been proposed that insulin is having an inhibitory effect on plasma ghrelin $(3,4)$, although studies have been conflicting (60-62). Ghrelin administration to humans has been shown to inhibit insulin secretion, but no effect on insulin response during OGTT was observed $(63,64)$. Co-administration of acylated and des-acyl ghrelin prevented the acute hyperglycaemic and hyperinsulinaemic effects of acylated and unacylated ghrelin when administered alone (65). Degree of insulin resistance or diabetes status could have an influence on the relationship between ghrelin and insulin, since insulin during hyperinsulinaemic-euglycaemic clamp tests decreased plasma ghrelin dose dependently in healthy humans, but not in type 2 diabetic patients, perhaps due to the presence of insulin resistance (66). It is therefore not clear whether insulin resistance plays a causal role in lower ghrelin concentrations, or whether ghrelin concentrations may be downregulated in insulin resistance as a physiological response to hyperinsulinaemic state.

As also seen in our study, subjects with insulin resistance or metabolic syndrome have lower ghrelin levels than normal weight controls $(25,27,32)$ and higher plasma ghrelin levels have been associated with increased insulin sensitivity $(34,36)$.

In our study, diet-induced weight loss did not result in an increase in plasma ghrelin levels; instead, we found that ghrelin concentrations in overweight/obese control subjects significantly decreased over the study period. Since our subjects were all insulin resistant, we could speculate that overweight/obese subjects with IGT or IFG experience a gradual decrease in plasma ghrelin levels, when they are not undergoing lifestyle changes. It may be that the absence of weight loss in obesity may further decrease plasma ghrelin levels over time. Supporting this hypothesis, the increased plasma ghrelin levels achieved by weight loss through dietary restrictions returned to baseline after a weight maintenance period of 6 months in a recent study (47). It has been proposed that an increase in circulating ghrelin after weight loss may constitute a secondary, counterregulatory mechanism preventing further weight loss (38). In fact, while ghrelin remained relatively stable, leptin serum levels decreased significantly upon dietinduced weight reduction in our study (data not shown). It is therefore tempting to speculate that the moderate weight loss experienced by our study participants, which was accompanied by beneficial perpetuation or changes respectively, in circulating appetite hormones was thus giving way to successfully maintain the lost weight.

In our study, no changes in plasma ghrelin levels were observed in the resistance or aerobic exercise groups. This may be partly explained by the absence of weight loss or low intensity of exercise, or it may suggest that exercise has a little effect on ghrelin concentrations.

It must be noted that the plasma ghrelin levels reflected in this study are total plasma ghrelin levels. When interpreting the results of this study, it should therefore be taken into consideration that even though the total circulating ghrelin levels did not change upon weight reduction or exercise intervention, it is also possible that acylated ghrelin levels or the acylated/unacylated ghrelin ratio changed. It is therefore recommended that future studies investigate the 
effect of weight reduction on the two forms of circulating ghrelin separately.

Measurement of only total ghrelin (acylated and nonacylated ghrelin) may contribute to the controversy regarding plasma ghrelin levels and insulin sensitivity or insulin resistance. Non-acylated and acylated ghrelin forms may, however, induce different physiological and metabolic effects $(65,67)$. Elevated acylated/nonacylated ghrelin ratios were associated with insulin resistance in obese or overweight subjects (29). Both total and non-acylated ghrelin were inversely related with insulin resistance, but acylated ghrelin and the acylated/non-acylated ghrelin ratio were associated with higher insulin resistance in subjects with metabolic syndrome (28). Even though acylated ghrelin seems to be more strongly associated with insulin resistance, non-acylated ghrelin nonetheless has some non-endocrine effects $(2,68)$.

To summarize, ghrelin and GHSR 1b, but not type 1a, mRNA expression was detected in PBMCs. The ghrelin mRNA expression was not determined by degree of obesity, measures of obesity, age or sex, and different lifestyle interventions and weight loss had no effect on the expression. Instead, ghrelin expression was modified by SNPs in the ghrelin gene promoter, thus explaining part of the variation in ghrelin expression in PBMCs, which was observed in our study subjects. Ghrelin expression in PBMCs correlated positively with expression of proinflammatory cytokines. The mechanisms, however, cannot be determined from our study.

Plasma ghrelin levels were associated with insulin resistance and other features of the metabolic syndrome cross-sectionally, but adiposity may more strongly predict ghrelin concentrations than insulin sensitivity over time. However, first-phase insulin secretion might also modulate plasma ghrelin levels. Moderate weight loss over a prolonged period of time did not increase plasma ghrelin levels, but the absence of weight loss in obesity along with metabolic syndrome may even decrease plasma ghrelin levels over time. Since ghrelin mRNA expression and plasma ghrelin concentration did not show an association, ghrelin expression in PBMCs suggests more an autocrine role for ghrelin in the immune microenvironment.

\section{Acknowledgements}

This work has been financially supported by grants from the Academy of Finland (number 211497 to M Uusitupa and number 209445 to M Kolehmainen), the Sigrid Juselius Foundation, the EVO-fund of Kuopio University Hospital ( $\mathrm{nr} 5179$, 5198), the Austrian Academy of Sciences, the Finnish Graduate School on Applied Bioscience, the Finnish Cultural Foundation, the Juho Vainio Foundation, the Yrjö Jahnsson Foundation and the Finnish Foundation for Diabetes Research. V D F de Mello was recipient of a scholarship from Conselho Nacional de Desenvolvimento Científico e Tecnológico, Brazil.

\section{References}

1 Higgins SC, Gueorguiev M \& Korbonits M. Ghrelin, the peripheral hunger hormone. Annals of Medicine 200739 116-136.

2 Kojima M \& Kangawa K. Ghrelin: structure and function. Physiological Reviews 200585 495-522.

3 Saad MF, Bernaba B, Hwu CM, Jinagouda S, Fahmi S, Kogosov E \& Boyadjian R. Insulin regulates plasma ghrelin concentration. Journal of Clinical Endocrinology and Metabolism $2002 \mathbf{8 7}$ 3997-4000.

4 Flanagan DE, Evans ML, Monsod TP, Rife F, Heptulla RA, Tamborlane WV \& Sherwin RS. The influence of insulin on circulating ghrelin. American Journal of Physiology. Endocrinology and Metabolism 2003284 E313-E316.

5 Kojima M, Hosoda H, Date Y, Nakazato M, Matsuo H \& Kangawa K. Ghrelin is a growth-hormone-releasing acylated peptide from stomach. Nature $1999 \mathbf{4 0 2} 656-660$.

6 Ukkola O, Ravussin E, Jacobson P, Perusse L, Rankinen T, Tschöp M, Heiman ML, Leon AS, Rao DC, Skinner JS, Wilmore JH, Sjöström L \& Bouchard C. Role of ghrelin polymorphisms in obesity based on three different studies. Obesity Research 200210 782-791.

7 Ukkola O, Ravussin E, Jacobson P, Snyder EE, Chagnon M, Sjöström L \& Bouchard C. Mutations in the preproghrelin/ghrelin gene associated with obesity in humans. Journal of Clinical Endocrinology and Metabolism 200186 3996-3999.

8 Kuzuya M, Ando F, Iguchi A \& Shimokata H. Preproghrelin Leu72Met variant contributes to overweight in middle-aged men of a Japanese large cohort. International Journal of Obesity $2006 \mathbf{3 0}$ $1609-1614$

9 Tang NP, Wang LS, Yang L, Gu HJ, Zhu HJ, Zhou B, Sun QM, Cong RH \& Wang B. Preproghrelin Leu72Met polymorphism in Chinese subjects with coronary artery disease and controls. Clinica Chimica Acta $2008 \mathbf{3 8 7} 42-47$.

10 Mager U, Kolehmainen M, Lindström J, Eriksson JG, Valle TT, Hämäläinen $\mathrm{H}$, Ilanne-Parikka $\mathrm{P}$, Keinänen-Kiukaanniemi $\mathrm{S}$, Tuomilehto JO, Pulkkinen L \& Uusitupa MI. Association between ghrelin gene variations and blood pressure in subjects with impaired glucose tolerance. American Journal of Hypertension 2006 19 920-926.

11 Kim SY, Jo DS, Hwang PH, Park JH, Park SK, Yi HK \& Lee DY. Preproghrelin Leu72Met polymorphism is not associated with type 2 diabetes mellitus. Metabolism 200655 366-370.

12 Mager U, Lindi V, Lindström J, Eriksson JG, Valle TT, Hämäläinen H, Ilanne-Parikka P, Keinänen-Kiukaanniemi S, Tuomilehto J, Laakso M, Pulkkinen L \& Uusitupa M. Association of the Leu72Met polymorphism of the ghrelin gene with the risk of Type 2 diabetes in subjects with impaired glucose tolerance in the Finnish Diabetes Prevention Study. Diabetic Medicine 200623 685-689.

13 Korbonits M, Gueorguiev M, O'Grady E, Lecoeur C, Swan DC, Mein CA, Weill J, Grossman AB \& Froguel P. A variation in the ghrelin gene increases weight and decreases insulin secretion in tall, obese children. Journal of Clinical Endocrinology and Metabolism $2002874005-4008$.

14 Pöykkö SM, Ukkola O, Kauma H, Savolainen MJ \& Kesäniemi YA. Ghrelin Arg 51Gln mutation is a risk factor for type 2 diabetes and hypertension in a random sample of middle-aged subjects. Diabetologia $2003 \mathbf{4 6} 455-458$.

15 Steinle NI, Pollin TI, O'Connell JR, Mitchell BD \& Shuldiner AR. Variants in the ghrelin gene are associated with metabolic syndrome in the Old Order Amish. Journal of Clinical Endocrinology and Metabolism $2005906672-6677$.

16 Bing C, Ambye L, Fenger M, Jørgensen T, Borch-Johnsen K, Madsbad S \& Urhammer SA. Large-scale studies of the Leu72Met 
polymorphism of the ghrelin gene in relation to the metabolic syndrome and associated quantitative traits. Diabetic Medicine 200522 1157-1160.

17 Gnanapavan S, Kola B, Bustin SA, Morris DG, McGee P, Fairclough P, Bhattacharya S, Carpenter R, Grossman AB \& Korbonits M. The tissue distribution of the mRNA of ghrelin and subtypes of its receptor, GHS-R, in humans. Journal of Clinical Endocrinology and Metabolism $2002 \mathbf{8 7} 2988$.

18 Hattori N, Saito T, Yagyu T, Jiang BH, Kitagawa K \& Inagaki C. GH, $\mathrm{GH}$ receptor, $\mathrm{GH}$ secretagogue receptor, and ghrelin expression in human $\mathrm{T}$ cells, B cells, and neutrophils. Journal of Clinical Endocrinology and Metabolism 200186 4284-4291.

19 Dixit VD, Schaffer EM, Pyle RS, Collins GD, Sakthivel SK, Palaniappan R, Lillard JW Jr \& Taub DD. Ghrelin inhibits leptinand activation-induced proinflammatory cytokine expression by human monocytes and T cells. Journal of Clinical Investigation 2004 $11457-66$.

20 Howard AD, Feighner SD, Cully DF, Arena JP, Liberator PA, Rosenblum CI, Hamelin M, Hreniuk DL, Palyha OC, Anderson J, Paress PS, Diaz C, Chou M, Liu KK, McKee KK, Pong SS, Chaung LY, Elbrecht A, Dashkevicz M, Heavens R, Rigby M, Sirinathsinghji DJ, Dean DC, Melillo DG, Patchett AA, Nargund R, Griffin PR, DeMartino JA, Gupta SK, Schaeffer JM, Smith RG \& Van der Ploeg LH. A receptor in pituitary and hypothalamus that functions in growth hormone release. Science 1996273 974-977.

21 van der Lely AJ, Tschöp M, Heiman ML \& Ghigo E. Biological, physiological, pathophysiological, and pharmacological aspects of ghrelin. Endocrine Reviews 200425 426-457.

22 Tschöp M, Weyer C, Tataranni PA, Devanarayan V, Ravussin E \& Heiman ML. Circulating ghrelin levels are decreased in human obesity. Diabetes 200150 707-709.

23 Shiiya T, Nakazato M, Mizuta M, Date Y, Mondal MS, Tanaka M, Nozoe S, Hosoda H, Kangawa K \& Matsukura S. Plasma ghrelin levels in lean and obese humans and the effect of glucose on ghrelin secretion. Journal of Clinical Endocrinology and Metabolism 200287 240-244.

24 Tentolouris N, Kokkinos A, Tsigos C, Kyriaki D, Doupis J, Raptis SA \& Katsilambros N. Differential effects of high-fat and highcarbohydrate content isoenergetic meals on plasma active ghrelin concentrations in lean and obese women. Hormone and Metabolic Research 200436 559-563.

25 Tesauro M, Schinzari F, Iantorno M, Rizza S, Melina D, Lauro D \& Cardillo C. Ghrelin improves endothelial function in patients with metabolic syndrome. Circulation 2005112 2986-2992.

26 Chu MC, Cosper P, Orio F, Carmina E \& Lobo RA. Insulin resistance in postmenopausal women with metabolic syndrome and the measurements of adiponectin, leptin, resistin, and ghrelin. American Journal of Obstetrics and Gynecology 2006194 100-104.

27 McLaughlin T, Abbasi F, Lamendola C, Frayo RS \& Cummings DE. Plasma ghrelin concentrations are decreased in insulin-resistant obese adults relative to equally obese insulin-sensitive controls. Journal of Clinical Endocrinology and Metabolism $2004 \mathbf{8 9}$ 1630-1635.

28 Barazzoni R, Zanetti M, Ferreira C, Vinci P, Pirulli A, Mucci M, Dore F, Fonda M, Ciocchi B, Cattin L \& Guarnieri G. Relationships between desacylated and acylated ghrelin and insulin sensitivity in the metabolic syndrome. Journal of Clinical Endocrinology and Metabolism 200792 3935-3940.

29 St-Pierre DH, Karelis AD, Coderre L, Malita F, Fontaine J, Mignault D, Brochu M, Bastard JP, Cianflone K, Doucet E, Imbeault P \& Rabasa-Lhoret R. Association of acylated and nonacylated ghrelin with insulin sensitivity in overweight and obese postmenopausal women. Journal of Clinical Endocrinology and Metabolism 200792 264-269.

30 Zahorska-Markiewicz B, Mizia-Stec K, Olszanecka-Glinianowicz M \& Janowska J. Effect of weight reduction on serum ghrelin and TNF- $\alpha$ concentrations in obese women. European Journal of Internal Medicine $200415172-175$.

31 Langenberg C, Bergstrom J, Laughlin GA \& Barrett-Connor E. Ghrelin and the metabolic syndrome in older adults. Journal of Clinical Endocrinology and Metabolism $2005906448-6453$.
32 Ukkola O, Pöykkö SM \& Kesäniemi YA. Low plasma ghrelin concentration is an indicator of the metabolic syndrome. Annals of Medicine 200638 274-279.

33 Katsuki A, Urakawa H, Gabazza EC, Murashima S, Nakatani K, Togashi K, Yano Y, Adachi Y \& Sumida Y. Circulating levels of active ghrelin is associated with abdominal adiposity, hyperinsulinemia and insulin resistance in patients with type 2 diabetes mellitus. European Journal of Endocrinology 2004151 573-577.

34 Purnell JQ, Weigle DS, Breen P \& Cummings DE. Ghrelin levels correlate with insulin levels, insulin resistance, and high-density lipoprotein cholesterol, but not with gender, menopausal status, or cortisol levels in humans. Journal of Clinical Endocrinology and Metabolism $2003 \mathbf{8 8} 5747-5752$.

35 Park HS, Lee KU, Kim YS \& Park CY. Relationships between fasting plasma ghrelin levels and metabolic parameters in children and adolescents. Metabolism 2005 54 925-929.

36 Pöykkö SM, Kellokoski E, Horkko S, Kauma H, Kesäniemi YA \& Ukkola O. Low plasma ghrelin is associated with insulin resistance, hypertension, and the prevalence of type 2 diabetes. Diabetes 2003 52 2546-2553.

37 Fagerberg B, Hulten LM \& Hulthe J. Plasma ghrelin, body fat, insulin resistance, and smoking in clinically healthy men: the atherosclerosis and insulin resistance study. Metabolism $2003 \mathbf{5 2}$ 1460-1463.

38 Cummings DE, Weigle DS, Frayo RS, Breen PA, Ma MK, Dellinger EP \& Purnell JQ. Plasma ghrelin levels after diet-induced weight loss or gastric bypass surgery. New England Journal of Medicine $2002 \mathbf{3 4 6} 1623-1630$.

39 Hansen TK, Dall R, Hosoda H, Kojima M, Kangawa K, Christiansen JS \& Jorgensen JO. Weight loss increases circulating levels of ghrelin in human obesity. Clinical Endocrinology $2002 \mathbf{5 6}$ 203-206.

40 Boden G, Sargrad K, Homko C, Mozzoli M \& Stein TP. Effect of a low-carbohydrate diet on appetite, blood glucose levels, and insulin resistance in obese patients with type 2 diabetes. Annals of Internal Medicine $2005 \mathbf{1 4 2} 403-411$.

41 Purnell JQ, Cummings D \& Weigle DS. Changes in 24-h areaunder-the-curve ghrelin values following diet-induced weight loss are associated with loss of fat-free mass, but not with changes in fat mass, insulin levels or insulin sensitivity. International Journal of Obesity 200731 385-389.

42 Hayes MR, Miller CK, Ulbrecht JS, Mauger JL, Parker-Klees L, Gutschall MD, Mitchell DC, Smiciklas-Wright H \& Covasa M. A carbohydrate-restricted diet alters gut peptides and adiposity signals in men and women with metabolic syndrome. Journal of Nutrition 2007137 1944-1950.

43 Santosa S, Demonty I, Lichtenstein AH, Cianflone K \& Jones PJ. An investigation of hormone and lipid associations after weight loss in women. Journal of the American College of Nutrition $2007 \mathbf{2 6}$ 250-258.

44 Weigle DS, Cummings DE, Newby PD, Breen PA, Frayo RS, Matthys CC, Callahan HS \& Purnell JQ. Roles of leptin and ghrelin in the loss of body weight caused by a low fat, high carbohydrate diet. Journal of Clinical Endocrinology and Metabolism $2003 \mathbf{8 8}$ $1577-1586$.

45 Reinehr T, Roth CL, Alexy U, Kersting M, Kiess W \& Andler W. Ghrelin levels before and after reduction of overweight due to a low-fat high-carbohydrate diet in obese children and adolescents. International Journal of Obesity $200529362-368$.

46 Reinehr T, de Sousa G \& Roth CL. Obestatin and ghrelin levels in obese children and adolescents before and after reduction of overweight. Clinical Endocrinology 200768 304-310.

47 Garcia JM, Iyer D, Poston WS, Marcelli M, Reeves R, Foreyt J \& Balasubramanyam A. Rise of plasma ghrelin with weight loss is not sustained during weight maintenance. Obesity $2006 \mathbf{1 4}$ 1716-1723.

48 Lejeune MP, Hukshorn CJ, Saris WH \& Westerterp-Plantenga MS. Effects of very low calorie diet induced body weight loss with or without human pegylated recombinant leptin treatment on changes in ghrelin and adiponectin concentrations. Physiology and Behavior $200791274-280$. 
49 Kraemer RR \& Castracane VD. Exercise and humoral mediators of peripheral energy balance: ghrelin and adiponectin. Experimental Biology and Medicine 2007232 184-194.

50 Mackelvie KJ, Meneilly GS, Elahi D, Wong AC, Barr SI \& Chanoine JP. Regulation of appetite in lean and obese adolescents after exercise: role of acylated and desacyl ghrelin. Journal of Clinical Endocrinology and Metabolism 200792 648-654.

51 Foster-Schubert KE, McTiernan A, Frayo RS, Schwartz RS, Rajan KB, Yasui Y, Tworoger SS \& Cummings DE. Human plasma ghrelin levels increase during a one-year exercise program. Journal of Clinical Endocrinology and Metabolism 200590 820-825.

52 Kim HJ, Lee S, Kim TW, Kim HH, Jeon TY, Yoon YS, Oh SW, Kwak H \& Lee JG. Effects of exercise-induced weight loss on acylated and unacylated ghrelin in overweight children. Clinical Endocrinology, 2007 (In Press).

53 Kolehmainen M, Salopuro T, Schwab US, Kekäläinen J, Kallio P, Laaksonen DE, Pulkkinen L, Lindi VI, Sivenius K, Mager U, Siitonen N, Niskanen L, Gylling H, Rauramaa R \& Uusitupa M. Weight reduction modulates expression of genes involved in extracellular matrix and cell death: the GENOBIN study. International Journal of Obesity 2007 (In Press).

54 Sarkkinen E, Schwab U, Niskanen L, Hannuksela M, Savolainen M, Kervinen K, Kesäniemi A \& Uusitupa MI. The effects of monounsaturated-fat enriched diet and polyunsaturated-fat enriched diet on lipid and glucose metabolism in subjects with impaired glucose tolerance. European Journal of Clinical Nutrition $1996 \mathbf{5 0} 592-598$.

55 Boston RC, Stefanovski D, Moate PJ, Sumner AE, Watanabe RM \& Bergman RN. MINMOD Millennium: a computer program to calculate glucose effectiveness and insulin sensitivity from the frequently sampled intravenous glucose tolerance test. Diabetes Technology \& Therapeutics 20035 1003-1015.

56 Cummings DE, Purnell JQ, Frayo RS, Schmidova K, Wisse BE \& Weigle DS. A preprandial rise in plasma ghrelin levels suggests a role in meal initiation in humans. Diabetes 200150 1714-1719.

57 Eady JJ, Wortley GM, Wormstone YM, Hughes JC, Astley SB, Foxall RJ, Doleman JF \& Elliott RM. Variation in gene expression profiles of peripheral blood mononuclear cells from healthy volunteers. Physiological Genomics 200522 402-411.

58 Li WG, Gavrila D, Liu X, Wang L, Gunnlaugsson S, Stoll LL, McCormick ML, Sigmund CD, Tang C \& Weintraub NL. Ghrelin inhibits proinflammatory responses and nuclear factor- $\kappa \mathrm{B}$ activation in human endothelial cells. Circulation $20041092221-2226$.

59 Leung PK, Chow KB, Lau PN, Chu KM, Chan CB, Cheng CH \& Wise $H$. The truncated ghrelin receptor polypeptide (GHS-R1b) acts as a dominant-negative mutant of the ghrelin receptor. Cellular Signalling 200719 1011-1022.
60 Briatore L, Andraghetti G \& Cordera R. Acute plasma glucose increase, but not early insulin response, regulates plasma ghrelin. European Journal of Endocrinology 2003149 403-406.

61 Caixas A, Bashore C, Nash W, Pi-Sunyer F \& Laferrere B. Insulin, unlike food intake, does not suppress ghrelin in human subjects. Journal of Clinical Endocrinology and Metabolism $2002 \mathbf{8 7} 1902$.

62 Schaller G, Schmidt A, Pleiner J, Woloszczuk W, Wolzt M \& Luger A. Plasma ghrelin concentrations are not regulated by glucose or insulin: a double-blind, placebo-controlled crossover clamp study. Diabetes 200352 16-20.

63 Broglio F, Arvat E, Benso A, Gottero C, Muccioli G, Papotti M, van der Lely AJ, Deghenghi R \& Ghigo E. Ghrelin, a natural GH secretagogue produced by the stomach, induces hyperglycemia and reduces insulin secretion in humans. Journal of Clinical Endocrinology and Metabolism 200186 5083-5086.

64 Broglio F, Gottero C, Benso A, Prodam F, Destefanis S, Gauna C, Maccario M, Deghenghi R, van der Lely AJ \& Ghigo E. Effects of ghrelin on the insulin and glycemic responses to glucose, arginine, or free fatty acids load in humans. Journal of Clinical Endocrinology and Metabolism $2003 \mathbf{8 8} 4268-4272$.

65 Gauna C, Meyler FM, Janssen JA, Delhanty PJ, Abribat T, van Koetsveld P, Hofland LJ, Broglio F, Ghigo E \& van der Lely AJ. Administration of acylated ghrelin reduces insulin sensitivity, whereas the combination of acylated plus unacylated ghrelin strongly improves insulin sensitivity. Journal of Clinical Endocrinology and Metabolism 200489 5035-5042.

66 Anderwald C, Brabant G, Bernroider E, Horn R, Brehm A, Waldhausl W \& Roden M. Insulin-dependent modulation of plasma ghrelin and leptin concentrations is less pronounced in type 2 diabetic patients. Diabetes 200352 1792-1798.

67 Gauna C, Delhanty PJ, Hofland LJ, Janssen JA, Broglio F, Ross RJ, Ghigo E \& van der Lely AJ. Ghrelin stimulates, whereas des-octanoyl ghrelin inhibits, glucose output by primary hepatocytes. Journal of Clinical Endocrinology and Metabolism 200590 1055-1060.

68 Broglio F, Gottero C, Prodam F, Gauna C, Muccioli G, Papotti M, Abribat T, Van Der Lely AJ \& Ghigo E. Non-acylated ghrelin counteracts the metabolic but not the neuroendocrine response to acylated ghrelin in humans. Journal of Clinical Endocrinology and Metabolism 200489 3062-3065.

Received 12 December 2007

Accepted 30 December 2007 